\title{
New Zr-based Glass-Forming Alloys Containing Gd and Sm
}

\author{
Luis César Rodríguez Aliaga*, Eric Marchezini Mazzer, Claudemiro Bolfarini, \\ Walter José Botta, Claudio Shyinti Kiminami \\ Department of Materials Engineering, Federal University of São Carlos - UFSCar, \\ São Carlos, SP, Brasil
}

Received: December 7, 2011; Revised: May 10, 2012

\begin{abstract}
The effect of minor additions of $\mathrm{Gd}$ and $\mathrm{Sm}$ on the glass-forming ability (GFA) of $\mathrm{Cu}-\mathrm{Zr}$-Al alloys is investigated here. The rationale for these additions is the fact that the atomic size distribution can increase GFA by changing the topology of the alloy as a function of cluster stability, which is tied to the electronegativity and ionic and covalent nature of alloys. Ingots with nominal compositions of $\mathrm{Cu}_{40} \mathrm{Zr}_{49} \mathrm{Al}_{10.5} \mathrm{Gd}_{0.5}, \mathrm{Cu}_{40} \mathrm{Zr}_{49} \mathrm{Al}_{10.5} \mathrm{Sm}_{0.5}$ and $\mathrm{Cu}_{39} \mathrm{Zr}_{50} \mathrm{Al}_{9} \mathrm{Gd}_{2}$ were prepared by arc-melting and rapidly quenched ribbons were produced by the melt-spinning technique. Bulk samples with a thickness of up to $10 \mathrm{~mm}$ were also produced by casting, using a wedge-shaped copper mold. The samples were characterized by differential scanning calorimetry, X-ray diffractometry and scanning electron microscopy. The three compositions showed a fully amorphous structure in the ribbons and a predominantly homogeneous amorphous structure with a thickness of up to $10 \mathrm{~mm}$, although some gadolinium oxide crystals as well as samarium compounds were found to be scattered in the amorphous matrix in 5-mm-thick samples. The amorphous phases in the alloys showed high thermal stability with a supercooled liquid region $\left(\Delta \mathrm{T}_{\mathrm{x}}\right)$ of about $70 \mathrm{~K}$.
\end{abstract}

Keywords: Cu-based alloys, glass-forming ability, bulk metallic glasses

\section{Introduction}

Bulk metallic glasses (BMGs) have been studied extensively due to their exceptional properties. Among BMGs, $\mathrm{Cu}$-based alloys stand out for their high strength, high thermal stability, high glass-forming ability (GFA), high corrosion resistance, and low costs ${ }^{1}$. The alloys of the $\mathrm{Cu}-\mathrm{Zr}-\mathrm{Al}$ system have a notably large supercooled liquid region, which may reach $70 \mathrm{~K}$, and good mechanical properties evidenced by their high fracture strength above $1880 \mathrm{MPa}^{[2]}$. Alloys with $\mathrm{Cu}-\mathrm{Zr}-\mathrm{Al}-\mathrm{Ag}$ composition have been reported to exhibit a remarkable increase in GFA due to the effect of $\mathrm{Ag}$ in the system ${ }^{3}$. The addition of Y to $\mathrm{Cu}-\mathrm{Zr}-\mathrm{Al}$ alloys reportedly improves their $\mathrm{GFA}^{4}$. Moreover, the addition of rare earth elements such as $\mathrm{La}, \mathrm{Ce}, \mathrm{Nd}$ and $\mathrm{Gd}$ $\left(\mathrm{Cu}_{45} \mathrm{Zr}_{48-\mathrm{x}} \mathrm{A}_{17} \mathrm{RE}_{\mathrm{x}}(\mathrm{RE}=\mathrm{La}, \mathrm{Ce}, \mathrm{Nd}\right.$, and $\mathrm{Gd}, 0 \leq \mathrm{x} \leq 5$ at. $\left.(\%))\right)$ has also been shown to increase the GFA ${ }^{5}$. Interesting results have been reported to the effect that the addition of $\mathrm{Gd}$ eliminates the harmful effect of oxygen by absorbing it and forming Gd-oxides, triggering heterogeneous nucleation of crystalline phases ${ }^{3}$, which leads to high GFA.

In this study, we added minor amounts of $\mathrm{Gd}$ and $\mathrm{Sm}$ to alloys of the $\mathrm{Cu}-\mathrm{Zr}-\mathrm{Al}$ system $\left(\mathrm{Cu}_{40} \mathrm{Zr}_{49} \mathrm{Al}_{10.5} \mathrm{Gd}_{0.5}\right.$, $\mathrm{Cu}_{40} \mathrm{Zr}_{49} \mathrm{Al}_{10.5} \mathrm{Sm}_{0.5}$ and $\mathrm{Cu}_{39} \mathrm{Zr}_{50} \mathrm{Al}_{9} \mathrm{Gd}_{2}$ ) and examined their influence on the GFA of these alloys in response to improved atomic distribution, which is reflected in topological instability. Samarium was introduced due to its physical properties of lower melting temperature and electronegativity than gadolinium, and because of its

*e-mail: aliaga@ufscar.br crystalline structure, which is rhombohedral as opposed to the hexagonal structure of $\mathrm{Gd}$. The metallic glass compositions were designed based on the synergic effect of topological instability, the $\lambda$-criterion, and the difference in the electronegativity of the elements ${ }^{6,7}$, combined with the average distribution of the chemical elements in the alloy. This criterion is strongly related with the efficient packing of atoms to form an icosahedral structure ${ }^{8,9}$. Close packing is a general criterion of packing efficiency. Traditionally, the highest package in crystalline structures is about $74 \%$ in face-centered cubic cells, which indicates densification. Amorphous materials have no basic cell; instead, they appear as clusters in a short-range order arrangement due to the differences in the electronegativities of their constituent alloys.

The $\lambda$-criterion was used to create minimum topological instability maps indicating the compositions in which topological instability reaches its maximum in the surrounding crystalline phases, and which are therefore expected to show better glass-forming ability. Topological instability indicates an atomic mismatch that induces stresses around an atom, which may be released by changing the occupancy of its nearest-neighbor shell. Thus, the GFA of metallic systems increases with increasing differences in size and is absent from elements with quasi-equal atomic radii. The difference in electronegativity among the elements $(\Delta \mathrm{e})$ in each particular composition is assumed to be related to the formation enthalpy $(\Delta \mathrm{H})$ and glass stability of the 
corresponding alloy ${ }^{5-7}$. Electronegativity describes the relativity ability of an atom to attract atoms in a chemical bond and can indicate the percentage of covalent bonding in the alloy ${ }^{10}$.

\section{Experimental Procedure}

High purity elements (above 99.9\%) were used to produce ingots with nominal compositions of $\mathrm{Cu}_{40} \mathrm{Zr}_{49} \mathrm{Al}_{10.5} \mathrm{Gd}_{0.5}, \mathrm{Cu}_{40} \mathrm{Zr}_{49} \mathrm{Al}_{10.5} \mathrm{Sm}_{0.5}$ and $\mathrm{Cu}_{39} \mathrm{Zr}_{50} \mathrm{Al}_{9} \mathrm{Gd}_{2}$, using arc-melting processes in Ti-gettered ultrapure argon atmosphere. Ribbons were then produced by rapid quenching on a copper wheel rotating at $30 \mathrm{~m} / \mathrm{s}$, using the melt-spinning technique. In addition, wedge-shaped bulk samples with a thickness of up to $10 \mathrm{~mm}$ were produced by casting, using a wedge-shaped copper mold and the suction technique. The resulting samples were characterized by $\mathrm{X}$-ray diffraction (XRD), scanning electron microscopy (SEM) and differential scanning calorimetry (DSC). XRD measurements were taken with a Rigaku diffractometer using $\mathrm{Cu}-\mathrm{K} \alpha$ radiation $(\lambda=1.5418 \AA)$ and $1^{\circ} \mathrm{C} / \mathrm{min}$ scan step from $10^{\circ}$ to $90^{\circ}(2 \theta)$. A Netzsch F203 calorimeter was used for thermal characterization in an ultrapure argon atmosphere, in a temperature range of 300 to $870 \mathrm{~K}$, at a heating rate of $40{ }^{\circ} \mathrm{C} / \mathrm{min}$. The SEM analysis was performed with a field emission gun (FEG) coupled to an energy dispersive spectroscopy (EDS) system to determine the real composition of the samples.

\section{Results and Discussion}

After producing the alloys, the ingots were subjected to thermal analysis in a temperature range of 25 to $1200 \mathrm{~K}$, applying a heating rate of $10 \mathrm{~K} / \mathrm{min}$, to determine their liquidus temperature ( $T l$, see Table 1 ). The 30 to $40 \mu \mathrm{m}$ thick and $3 \mathrm{~mm}$ wide ribbons containing Gd exhibited brittleness, while the ribbons containing Sm exhibited ductility, as evidenced by their bending strength at 180 degrees without breaking. The XRD and DSC analyses (not shown here) indicated that the structure of both samples was fully amorphous, and the intensity of their diffraction patterns were used to determine the percentage of crystalline phases in the bulk wedge-shaped samples.

Figure 1 depicts XRD patterns of the $\mathrm{Cu}_{40} \mathrm{Zr}_{49} \mathrm{Al}_{10.5} \mathrm{Gd}_{0.5}$ and $\mathrm{Cu}_{40} \mathrm{Zr}_{49} \mathrm{Al}_{10.5} \mathrm{Sm}_{0.5}$ samples. These curves show the evolution of the structure in the core of the wedge bulk samples, corresponding to small intervals of the thickness $(\Delta \mathrm{X})$. As can be seen, the amorphous structure prevails up to a thickness of $10 \mathrm{~mm}$, although small peaks corresponding to an unidentified crystalline phase appear on the thicker part of the $\mathrm{Cu}_{40} \mathrm{Zr}_{49} \mathrm{Al}_{10.5} \mathrm{Gd}_{0.5}$ sample. It is important to note that the $\mathrm{Cu}_{39} \mathrm{Zr}_{50} \mathrm{Al}_{9} \mathrm{Gd}_{2}$ shows low GFA in the amorphous structure up to $3 \mathrm{~mm}$ of thickness, at which point the structure of the sample becomes fully crystalline (results not shown).

Figure 2 a shows the DSC thermograms corresponding to different thicknesses along the axis of the wedge bulk samples. The presence of Gd clearly leads to the formation of a glassy structure up to $10 \mathrm{~mm}$ of thickness, although this amorphous phase undergoes only minor changes throughout the wedge. This modification is attributed to changes in composition or atomic arrangement (i.e., the metastability of the amorphous structure is influenced by the greater amount of crystalline phases), or possibly by differences in the free volume due to non-uniform cooling rates. Furthermore, while the crystallization of the 5-mm-thick amorphous phase occurs in one stage, the same transformation occurs in two stages in the 10 -mm-thick phase, indicating that the

Table 1. Thermal parameters of the alloys obtained at $5 \mathrm{~mm}$ thickness sample.

\begin{tabular}{ccccccc}
\hline Alloy & $\mathbf{T g}(\mathbf{K})$ & $\mathbf{T x}(\mathbf{K})$ & $\mathbf{T l} *(\mathbf{K})$ & $\Delta \mathbf{T x}(\mathbf{K})$ & $\operatorname{Trg}\left(\mathbf{T}_{\mathbf{g}} / \mathbf{T}_{\mathbf{l}}\right)$ & $\gamma\left(\mathbf{T}_{\mathbf{g}} /\left(\mathbf{T}_{\mathbf{x}}+\mathbf{T}_{\mathbf{1}}\right)\right)$ \\
\hline $\mathrm{Cu}_{39} \mathrm{Zr}_{50} \mathrm{Al}_{9} \mathrm{Gd}_{2}$ & 688 & 778 & 1178 & 90 & 0.584 & 0.417 \\
$\mathrm{Cu}_{40} \mathrm{Zr}_{49} \mathrm{Al}_{10.5} \mathrm{Gd}_{0.5}$ & 688 & 771 & 1171 & 83 & 0.587 & 0.415 \\
$\mathrm{Cu}_{40} \mathrm{Zr}_{49} \mathrm{Al}_{10.5} \mathrm{Sm}_{0.5}$ & 710 & 770 & 1165 & 60 & 0.609 & 0.410 \\
\hline
\end{tabular}

*Measurements carried out at heating rate of $10 \mathrm{~K} / \mathrm{min}$.

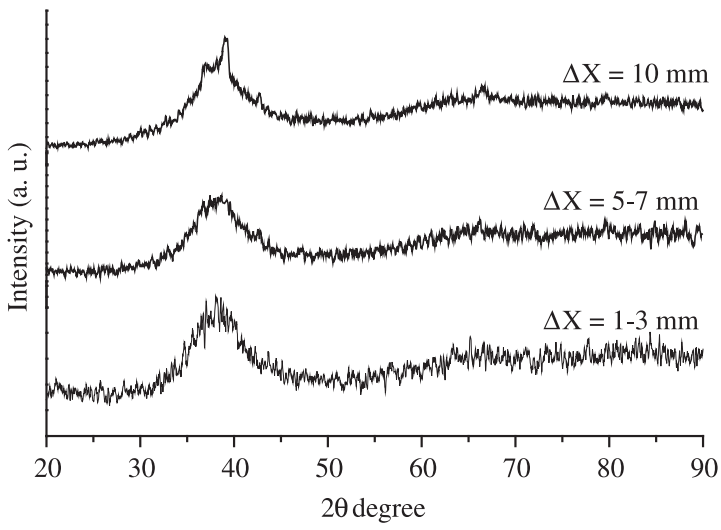

(a)

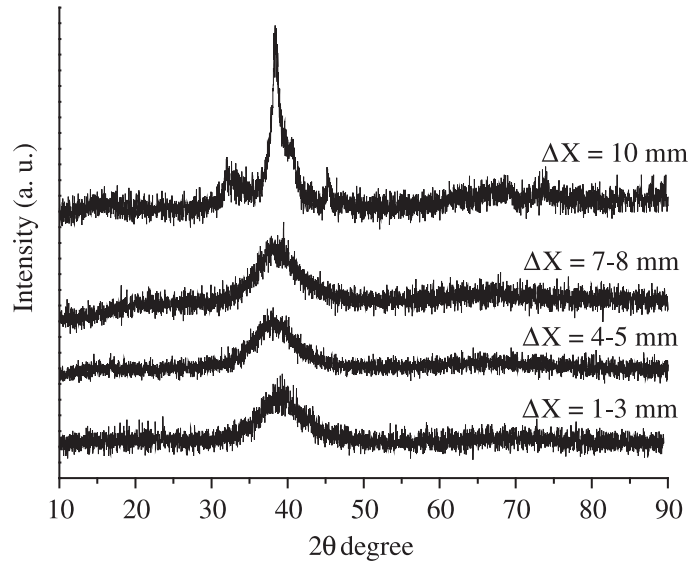

(b)

Figure 1. $\mathrm{XRD}$ patterns of (a) $\mathrm{Cu}_{40} \mathrm{Zr}_{49} \mathrm{Al}_{10.5} \mathrm{Gd}_{0.5}$ and (b) $\mathrm{Cu}_{40} \mathrm{Zr}_{49} \mathrm{Al}_{10.5} \mathrm{Sm}_{0.5} . \Delta \mathrm{X}=$ thickness sample where the measurement was carried out. 
compositional change in the amorphous phase takes place in this range of the sample.

With regard to the alloy containing $\mathrm{Sm}$, the composition of the amorphous phase shows no evidence of changes. The crystallization peaks remain similar, and the only visible changes are in the energy of transformation due to the difference in crystalline phase fractions, as indicated in the XRD patterns.

Table 1 summarizes the thermal parameters determined from the DSC analysis of the compositions in 5-mm-thick samples.

The three relative thermal parameters in Table $1, \Delta \mathrm{T}_{\mathrm{x}}$, $\mathrm{T}_{\mathrm{rg}}$ and $\gamma$, correspond to the theoretical glass-forming ability of these alloys. The temperature interval of the supercooled liquid region represents the thermal stability of the glassy phase of these alloys. The reduced glass transition temperature, $\mathrm{T}_{\mathrm{rg}}=\mathrm{T}_{\mathrm{g}} / \mathrm{T}_{1}$, considers the nucleation frequency and crystal growth of a melt, which is the inverse of the viscosity of the liquid. Lastly, the $\gamma$ parameter considers both the stability and the resistance to crystallization of the liquid. Although these parameters were measured after the amorphous phase was obtained, they allow for a good estimation of the GFA of the alloys.

For the formation of the BMGs, the value of $\gamma$ is between 0.350 and 0.500 , while $\Delta \mathrm{T}_{\mathrm{x}}$ varies from 16.3 to $117 \mathrm{~K}$ and $\mathrm{T}_{\mathrm{rg}}$ ranges from 0.503 to $0.609^{[11]}$. As can be seen, the parameters of the alloys of this study are in good agreement with these values, thus showing a good GFA.

Figures 3 and 4 show SEM micrographs of the $\mathrm{Cu}_{40} \mathrm{Zr}_{49} \mathrm{Al}_{10.5} \mathrm{Gd}_{0.5}$ and $\mathrm{Cu}_{40} \mathrm{Zr}_{49} \mathrm{Al}_{10.5} \mathrm{Sm}_{0.5}$ samples. The images were recorded on the central axis of the bulk samples, starting from the thinnest section and moving up to the thickest section of the bulk samples. From the tip of the bulk sample up to a thickness of $5 \mathrm{~mm}$, both compositions show a fully amorphous structure. However, as the thickness increases, the two samples show clearly visible differences.
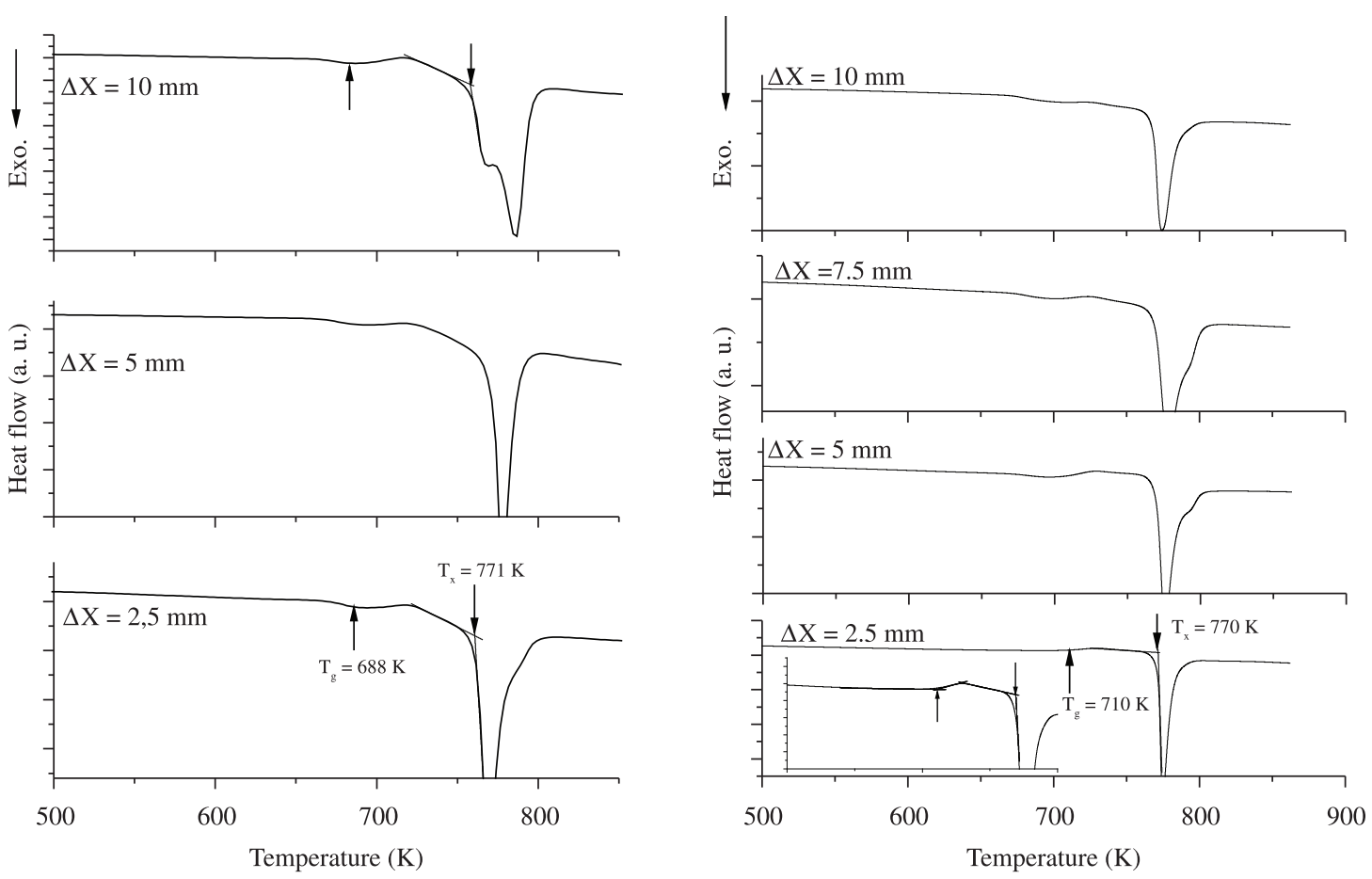

(a)

(b)

Figure 2. Thermograms of DSC at a heating rate of $40 \mathrm{~K} \cdot \mathrm{s}^{-1}$ of (a) $\mathrm{Cu}_{40} \mathrm{Zr}_{49} \mathrm{Al}_{10.5} \mathrm{Gd}_{0.5}$ and (b) $\mathrm{Cu}_{40} \mathrm{Zr}_{49} \mathrm{Al}_{10.5} \mathrm{Sm}_{0.5}$.

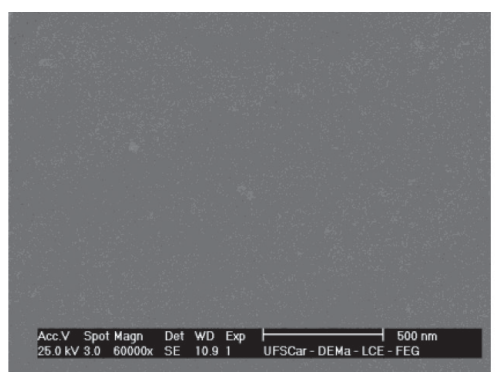

(a)

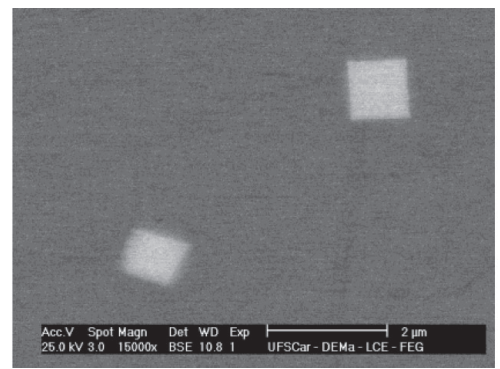

(b)

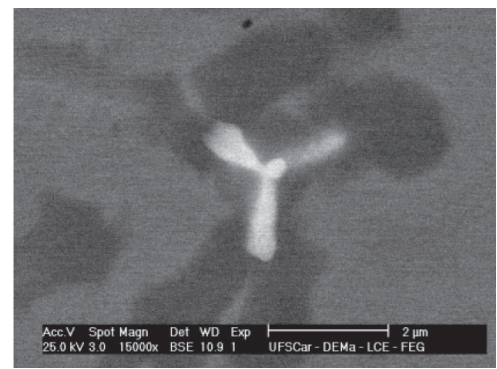

(c)

Figure 3. $\mathrm{SEM}$ images of a $\mathrm{Cu}_{40} \mathrm{Zr}_{49} \mathrm{Al}_{10.5} \mathrm{Gd}_{0.5}$ cast wedge samples. 


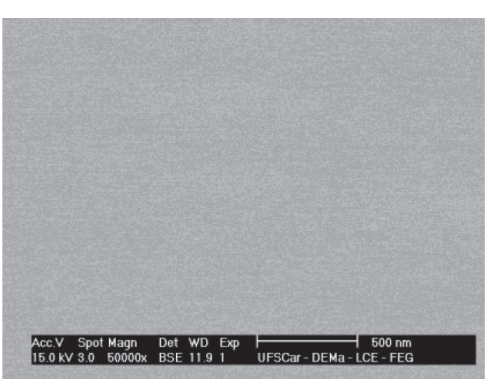

(a)

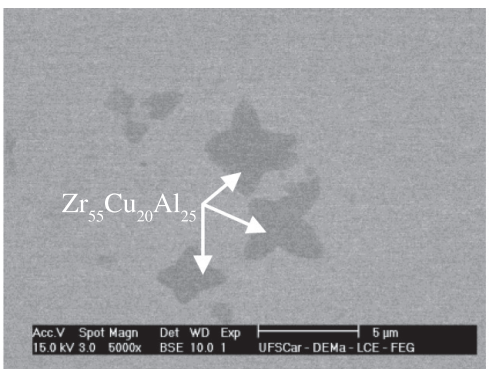

(b)

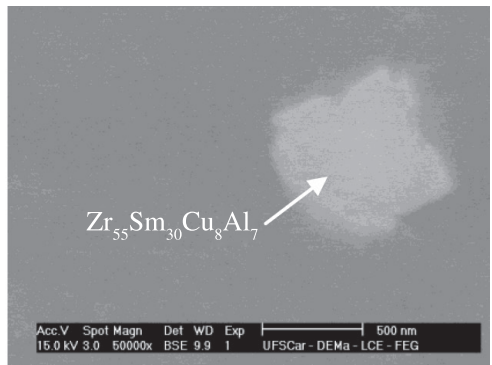

(c)

Figure 4. $\mathrm{SEM}$ images of a $\mathrm{Cu}_{40} \mathrm{Zr}_{49} \mathrm{Al}_{10.5} \mathrm{Sm}_{0.5}$ cast wedge samples.

The alloy containing Gd shows the presence a small volumetric fraction of Gd-oxide phase, which increases toward the thicker section of the sample. These oxide phases affected the alloy's mechanical behavior, causing it to become embrittled. In contrast, the sample containing $\mathrm{Sm}$ shows no evidence of oxides in the thinner portion of the sample. Instead, it shows a $\mathrm{Zr}$-rich ternary phase in the $\mathrm{Zr}_{55} \mathrm{Cu}_{20} \mathrm{Al}_{25}$ composition, which, in the $\mathrm{Zr}_{55} \mathrm{Sm}_{30} \mathrm{Cu}_{8} \mathrm{Al}_{7}$ composition, is visible only in the thicker part of the sample. It is worth noting that the Sm-containing alloy shows no brittle behavior, despite the influence of $\mathrm{Zr}$-rich ternary crystalline phases. It is well known that the strain at failure of BMG composites is strongly affected by the volume fraction of secondary phase crystalline particles, as well as particle size and distribution in the amorphous matrix ${ }^{12}$. In this study, the oxide crystalline phases were found to have a detrimental effect on the mechanical response of the BMG.

The alloys under study show strong topological similarities, with very similar values of $\lambda x \Delta X$-parameter (0.1149 for $\mathrm{Cu}_{40} \mathrm{Zr}_{39} \mathrm{Al}_{10.5} \mathrm{Gd}_{0.5}$ and 0.1150 for $\mathrm{Cu}_{40} \mathrm{Zr}_{39} \mathrm{Al}_{10.5} \mathrm{Sm}_{0.5}$ ) and a $R a$ of 0.1465 for $\mathrm{Cu}_{40} \mathrm{Zr}_{39} \mathrm{Al}_{10.5} \mathrm{Gd}_{0.5}$ and of 0.1456 for $\mathrm{Cu}_{40} \mathrm{Zr}_{39} \mathrm{Al}_{10.5} \mathrm{Gd}_{0.5}$. Since a value of 0.15 corresponds to a fully icosahedral cluster arrangement, the alloys of this study are expected to contain a large percentage of such clusters. Wang et al. ${ }^{9}$ reported that the introduction of aluminum in $\mathrm{Cu}-\mathrm{Zr}$ alloys favors the improved distribution of atoms with an icosahedral-like arrangement, thus leading to high GFA. However, this does not suffice to explain the differences in the GFA behavior of the alloys, which therefore require the exploration of other aspects.

On the other hand, an analysis of the results clearly indicates that the GFA of multi-component systems cannot simply be considered as the resistance to precipitation of crystalline phases from undercooled liquids. It has also been found that rare earth (RE) elements can react with oxygen impurities, forming innocuous RE oxides that enhance the GFA of alloys ${ }^{13,14}$.

Comparing the influence of the ionicity (IC) induced by $\mathrm{Gd}$ and Sm through the well known relation ${ }^{15}: \% \mathrm{IC}=100$. $\left\{1-\exp \left[0.25\left(\chi_{A}-\chi_{B}\right)^{2}\right]\right\}$, where $\chi$ is the electronegativity of elements A and B, provides a clearer picture of this aspect. Ionic bonds are usually formed when the difference in electronegativity between two atoms in a diatomic molecule is greater than approximately 2.0. The greater this difference the more ionic the bond. Applying the above relation to the alloys of this system, it was found that the \% IC of $\mathrm{Cu}-\mathrm{Gd}=11.5 \%$, that of $\mathrm{Cu}-\mathrm{Sm}=12.47 \%, \mathrm{Zr}-\mathrm{Gd}=0.42 \%$, and $\mathrm{Zr}-\mathrm{Sm}=0.64 \%$. This indicates that Sm slightly increased the ionicity, which can be attributed to the better distribution of icosahedral clusters, which have an excellent packing distribution, as indicated by the ideal average atomic ratio of 0.15 . On the other hand, the nearest-neighbor atomic arrangement in a given metal or alloy is singularly dictated by its covalent bonds, which, in turn, determine its crystal structure. The strength of covalent bonds in a given metal or alloy ultimately dictates its melting temperature. It is possible that the higher GFA of metallic glasses is closely tied to the ratio of the three types of chemical bonds, which may give rise to a specific structural arrangement, although this is simply a supposition.

\section{Conclusions}

Rapidly quenched ribbons and bulk samples of $\mathrm{Cu}_{40} \mathrm{Zr}_{49} \mathrm{Al}_{10.5} \mathrm{Gd}_{0.5}$ and $\mathrm{Cu}_{40} \mathrm{Zr}_{49} \mathrm{Al}_{10.5} \mathrm{Sm}_{0.5}$, with thicknesses of up to $10 \mathrm{~mm}$, showed a fully amorphous structure in the ribbons of the two compositions. In addition, bulk samples with a thickness of up to $10 \mathrm{~mm}$ showed a predominantly homogeneous amorphous structure, although some gadolinium and samarium oxide crystals were found distributed in the amorphous matrix of 5-mm-thick samples. The amorphous phases in the alloys showed high thermal stability in the supercooled liquid region $\left(\Delta \mathrm{T}_{\mathrm{x}}\right)$ at about $70 \mathrm{~K}$. The $\mathrm{Cu}_{39} \mathrm{Zr}_{9} \mathrm{Al}_{9} \mathrm{Gd}_{2}$ composition showed poor GFA, but high thermal stability at $90 \mathrm{~K}$ of $\Delta \mathrm{T}_{\mathrm{x}}$.

\section{Acknowledgements}

The authors thank the Brazilian research funding agencies FAPESP, CNPq and CAPES for granting a fellowship and financing the thematic project no. 07/59594-0. 


\section{References}

1. Fu HM, Wang H, Zhanga HF and Hu ZQ. The effect of Gd addition on the glass-forming ability of $\mathrm{Cu}-\mathrm{Zr}-\mathrm{Al}$ alloy. Scripta Materialia. 2006; 55:147-150. http://dx.doi.org/10.1016/j. scriptamat.2006.03.052

2. Zhang W, Qin C, Zhang X and Inoue A. Effects of additional noble elements on the thermal stability and mechanical properties of $\mathrm{Cu}-\mathrm{Zr}-\mathrm{Al}$ bulk glassy alloys. Materials Science and Engineering A. 2007; 631:449-451.

3. Sung DS, Kwon OJ, Fleury E, Kim KB and Lee JC. Enhancement of the glass forming ability of $\mathrm{Cu}-\mathrm{Zr}-\mathrm{Al}$ alloys by $\mathrm{Ag}$ addition. Metals and materials International. 2004; 10(6):575-79.

4. Xu DH, Duan G and Johanson WL. Unusual glass-forming ability of bulk amorphous alloys based on ordinary metal copper. Physical Review Letters. 2004; 92:245504-1. http:// dx.doi.org/10.1103/PhysRevLett.92.245504

5. Xu X, Chen LY, Zhang GQ, Wang LN, Jiang JZ. Formation of bulk metallic glasses in $\mathrm{Cu}_{45} \mathrm{Zr}_{48-\mathrm{x}} \mathrm{Al}_{7} \mathrm{RE}_{\mathrm{x}}(\mathrm{RE}=\mathrm{La}, \mathrm{Ce}, \mathrm{Nd}$, $\mathrm{Gd}$ and $0 \leq \mathrm{x} \leq 5$ at.\%). Intermetallics. 2007; 15:1066-1070. http://dx.doi.org/10.1016/j.intermet.2006.12.010

6. De Oliveira MF, Pereira FS, Bolfarini C, Kiminami CS and Botta WJ. Topological instability, average electronegativity difference and glass forming ability of amorphous alloys. Intermettalics. 2009; 17:183-185. http://dx.doi.org/10.1016/j. intermet.2008.09.013

7. De Oliveira MF, Pereira FS, Ramasco BT, Kiminami CS, Botta WJ and Bolfarini C. Glass formation of alloys selected by lambda and electronegativity criteria in the $\mathrm{Ti}-\mathrm{Zr}-\mathrm{Fe}-\mathrm{Co}$ system. Journal of Alloys and Compounds. 2010; 495:316-318. http://dx.doi.org/10.1016/j.jallcom.2009.10.255
8. Fang S, Xiao X, Xia L, Li W and Dong Y. Relationship between the widths of supercooled liquid regions and bond parameters of Mg-based bulk metallic glasses. Journal of Non-Crystalline Solids. 2003; 321:120-125. http://dx.doi.org/10.1016/S00223093(03)00155-8

9. Wang XD, Jiang QK, Cao QP, Bednarcik J, Franz H and Jiang JZ. Atomic structure and glass forming ability of $\mathrm{Cu}_{46} \mathrm{Zr}_{46} \mathrm{Al}_{8}$ bulk metallic glass. Journal of Applied Physics. 2008; 104:093519. http://dx.doi.org/10.1063/1.3009320

10. Wang FE. Bonding Theory for Metals and Alloys. University of Michigan, Elsevier; 2005.

11. Lu Z and Liu C. A new glass-forming ability criterion for bulk metallic glasses. Acta Materialia. 2002; 50:3501-3512. http:// dx.doi.org/10.1016/S1359-6454(02)00166-0

12. Castellero A, Baser TA, Das J, Matteis P, Eckert J, Battezzati $\mathrm{L}$ et al. Role of crystalline precipitates on the mechanical properties of $\left(\mathrm{Cu}_{0.50} \mathrm{Zr}_{0.50}\right)_{100-\mathrm{x}} \mathrm{Al}_{\mathrm{x}}(\mathrm{x}=4,5,7)$ bulk metallic glasses. Journal of Alloys and Compounds. 2011; 509:S99-S104. http:// dx.doi.org/10.1016/j.jallcom.2011.01.085

13. Xu Y, Wang Y, Liu X, Chen G and Zhang Y. Effects of additional elements $(\mathrm{M})$ on the thermal stability and structure of $\left(\mathrm{Zr}_{2.2} \mathrm{Cu}_{39.1} \mathrm{Al}_{8.7}\right)_{100-\mathrm{x}} \mathrm{M}_{\mathrm{x}}(\mathrm{M}=\mathrm{Ag}, \mathrm{Be}, \mathrm{Gd}, \mathrm{x}=8,7,2)$ amorphous alloys. Journal of Material Scienchttp. http:// dx.doi.org/10.1007/s10853-009-3523-7e. 2009; 44:3861-3866.

14. Chen J, Zhang Y, He JP, Yao KF, Wei BC and Chen GL. Metallographic analysis of $\mathrm{Cu}-\mathrm{Zr}-\mathrm{Al}$ bulk amorphous alloys with yttrium addition. Scripta Materialia. 2006; 54:1351-1355. http://dx.doi.org/10.1016/j.scriptamat.2005.12.002

15. Mitchel BS. An introduction to materials engineering and science for chemical and materials engineers. John Wiley \& Sons Inc. Publication; 2004. 